\title{
The Illusion of Diffusion in Information Systems Research
}

\author{
Tom McMaster \\ Information Systems Institute, University of Salford, M5 4WT, UK
}

Key words: Diffusion, diffusionism, colonialism, actor-network theory, SSM, Scandinavian tradition

\begin{abstract}
It is argued here that many of the ideas behind diffusion are remnants of European colonialism. As such they reflect a power imbalance in the relationships between users and traditional IS developers that we would be well-advised to rethink in favour of more participative and democratic design and development processes.
\end{abstract}

\section{INTRODUCTION}

Diffusionism does not consist of a single idea. It is a hugely dominant and pervasive set of concepts that have influenced, and continue to influence many of the disciplines and worldviews that are found in the cultural institutions of modern Western societies. Not only do these include the fields of anthropology, sociology, geography, education, and marketing among others (Rogers, 1995, pp.42-43), but it is the contention here that these ideas also influence how we see the world in much more subtle and ubiquitous ways. Diffusionist thinking may well have become part of the mental furniture of our everyday lives, and if so, it therefore profoundly affects the way that we see and how we interpret our surroundings. Why this might be so, relates to several hundreds of years of being inculcated into ideas that Western Europe is superior to the rest of the world, and that its citizens have enjoyed an inherent right, indeed, have had a moral obligation to colonize everywhere else. The arguments will be presented during the course of this paper, but for the moment a useful example to illustrate the point might be

The original version of this chapter was revised: The copyright line was incorrect. This has been corrected. The Erratum to this chapter is available at DOI: 10.1007/978-0-387-35404-0_19 
provided by considering the traditional belief that a teacher standing in front of a class is somehow the source of (or at least a conduit for) knowledge - a common enough 'diffusionist' view - but one nevertheless that after a few moments of considered reflection will no doubt be recognized for the fanciful notion that it actually is!

The extreme ubiquitousness of these handmaidens of diffusionism those assumptions and beliefs that have pretty well imbued it with all the qualities of being a self-evident truth, have meant that scholars almost never question it. Instead they conduct studies into matters that derive from, and / or are dependent upon the implicit acceptance of diffusion, such as, 'rates of adoption', and other such detail that form the subject of much of the diffusion literature. By doing so it is argued here, they perpetuate the illusion that diffusionism is somehow more than the pseudo-science that it is taken to be in this paper.

Here we are concerned with these matters insofar as they affect and impinge on issues that concern the information systems (IS) community at large, and in particular, IS researchers. At one level this paper is intended to provide a non-Rogerian introductory account of the tradition and history of diffusion - one that would almost certainly never be found in contemporary diffusionist work. At another it is intended to provoke a debate among IS diffusion scholars by presenting a view of diffusion that is altogether different and far less sanitized than that which is generally promoted. A few words then about the motivation and the content of the paper are obviously in order.

Briefly, concepts of diffusion are incompatible with those of actornetwork theory (ANT - see for example Latour, 1987, 1993), an approach to thinking about the world to which this author subscribes (Vidgen \& McMaster, 1996, McMaster et al., 1997a, McMaster et al., 1999). For example at a fundamental level, diffusionism takes 'facts' to be pre-existing (often hidden), waiting to be uncovered at some point by heroic discoverers and inventors - human characters that are deemed important and necessary to the diffusionist mindset. It is the mechanisms behind the 'dispersal' of these facts (ideas, products, artifacts etc.) through society that constitute the essence of the diffusionist model.

ANT on the other hand has no need for inventors and other heroes, since there are no facts lying around waiting to be invented discovered or otherwise found. Facts are instead dynamic networks formed by the alignment of allied interests (the 'network'). As new human and non-human candidates (or actants as they are sometimes called) along with their respective interests join and converge with the general trajectory of the lengthening network, so its shapes, meanings and messages change. Over 
time the network hardens into what is ultimately and essentially a 'black box' or what we come to think of as a 'fact'.

In this sense the ideas of actor-network theory are more closely related to radical constructivist thinking than to the positivistic determinism underpinning classical diffusionist thought. Since the views represented in the two theories are mutually exclusive, it follows at least from an actornetwork perspective, that there must be an explanation other than that promoted by diffusionists for the preponderance and dominance of their views. This paper thus is an attempt to tell a missing story. It does not purport to be 'the truth' (a diffusionist concept). It is instead rather more in the tradition of soft systems thinking (Checkland, 1981, Checkland \&, Scholes 1990, Checkland \& Holwell, 1998), and other interpretive approaches to research that encourage multiple perspectives on the issues under investigation. It is the opinion and indeed the experience of this author that such approaches can, and generally do enrich our understanding of the objects of our study.

Here then, we consider something of the origins of diffusion theory, a dimension generally missing from modern diffusionist work. The paper is organized in the following way: the next section presents the background and a starting point for our story, noting that claims for the study of diffusionism may not be as mature as some sources would have us believe. Section 3 presents a historical account of diffusionist thinking that provides a context for seeing diffusion as part of a rarely uncontentious tradition extending back over several hundreds of years. Section 4 encapsulates the various arguments used to justify the superiority of European colonizers over those whose lands and property they coveted, and provides for us a possible framework for examining links between colonization and some contemporary IS/IT practices. In section 5 we construct a model of diffusion that shows its relationship with colonization, and in the final section we consider in conclusion, what this might mean for IS research and practice.

Let us begin by looking at the background to some of these issues.

\section{BACKGROUND}

Given Rogers's claim for diffusion that "no other field...represents more effort by more scholars in more disciplines in more nations" (Rogers, 1995, p.xv), it is perhaps not surprising to note the formation of IS-oriented diffusion interest groups over recent years. These include DIGIT (Diffusion Interest Group in Information Technology) and the IFIP Working Group 8.6, which focuses on the 'diffusion, adoption and implementation of information technologies' (IT). In addition there are a considerable number of 
researchers in the IS domain who work on matters related to the diffusion of IT outside of any formally organized group. What might be remarkable though, is that when we examine the outputs of (at least one of) these groups, we find little to support the kind of shared, coherent background knowledge that such a claim might reasonable lead us to expect. Consider the following table (table 1) which is a citations frequency list based on the first three IFIP WG8.6 meetings* (Levine, 1994, Kautz \& Pries-Heje, 1996, McMaster et al., 1997b).

Table 1. IFIP 8.6 proceedings citations frequency

\begin{tabular}{|c|c|c|c|c|c|}
\hline \multicolumn{2}{|l|}{ Levine, 1994} & \multicolumn{2}{|c|}{ Kautz \& Pries-Heje, 1996} & \multicolumn{2}{|c|}{ McMaster et al, 1997} \\
\hline Reference & Frequency & Reference & Frequency & Reference & Frequency \\
\hline Attewell 1992 & 5 & Rogers 1983 & 5 & Rogers 1983 & 11 \\
\hline $\begin{array}{l}\text { Kwon \& } \\
\text { Zmud } 1987\end{array}$ & 4 & $\begin{array}{l}\text { Kwon \& } \\
\text { Zmud } 1987\end{array}$ & 3 & Attewell 1992 & 4 \\
\hline Rogers 1983 & 4 & Others $* 8$ & 2 & $\begin{array}{l}\text { Kautz \& } \\
\text { McMaster } \\
1994\end{array}$ & 3 \\
\hline Fichman 1992 & 3 & Others $* 315$ & 1 & Rogers 1995 & 3 \\
\hline $\begin{array}{l}\text { Ives \& Olsen } \\
1984\end{array}$ & 3 & & & Zmud 1984 & 3 \\
\hline Markus 1983 & 3 & & & Others * 18 & 2 \\
\hline $\begin{array}{l}\text { Tornatzky \& } \\
\text { Klein } 1982\end{array}$ & 3 & & & & \\
\hline Others * 40 & 2 & & & & \\
\hline Others * 503 & 1 & & & & \\
\hline
\end{tabular}

The Levine book contains some 30 papers offering between them 550 unique references, of which 503 , that is $92 \%$, are single 'one-off' citations. The other 47 references are variously cited more than once, thus; 1 reference is cited 5 times, 2 references 4 times, 4 references 3 times and 40 references twice. The Kautz and Pries-Heje book fares rather 'less well' with 325 single references in 12 published papers. 315 , that is $97 \%$, are one-off references, the other 10 are cited more than once; 1 reference appears 5 times, 1 reference 3 times, and 8 references twice. In the final offering, McMaster et al., there are 22 papers containing 458 references of which $435(95 \%)$ are again 'one-off's' with 23 replicated; 1 reference 11 times, 1 reference 4 times, 3 references 3 times, and 18 references twice.

Remarkable more perhaps for what might be missing than from what is actually there, such an apparent absence of common knowledge might seem astonishing, but a note of caution requires that we take care what we interpret from these figures. The sample is limited to 64 papers in IFIP

\footnotetext{
* We exclude the 4th meeting, the joint IFIP8.2/8.6 event held in Helsinki in 1999, because of the difficulty in separating the various submissions into their respective camps.
} 
WG8.6 publication, so this clearly does not provide conclusive evidence of a lack of common knowledge in the field. No, but neither can we entirely dismiss what small evidence we might have, since this group was formed specifically to accommodate researchers in the diffusion of IS/IT. Also, a not unreasonable argument might suggest that 64 papers provides us with a perfectly fair and reasonable sample. What we can do, is to note that there seems on the face of it to be some discrepancy between what we might expect (given Rogers's claim), and the reality on the ground. We should also note that the picture could be changed. If for example we were to remove 'self-references' from the data set, then the result would be that the paucity of 'overlap' (in background knowledge) would be even more marked than it now is.

What then can, or are we to make of diffusion and its claims? Let us consider something of the history and tradition of diffusionist thought.

\section{A DIFFUSIONIST TRADITION}

Rogers (1995, pp. 39-40) attributes the beginnings of diffusionist thinking to Jean-Gabriel de Tarde, a French sociologist and magistrate who became professor of modern philosophy at the Collège de France in 1900. What is interesting and significant for us, is that Tarde held 'invention' to be the source of all progress ('progress' itself let us note, is a quintessentially Victorian creation - see Bowler, 1989). Extremely few people (Tarde thought about one person in a hundred) are inventive, others merely imitate. These views were reflected in his best known work "The Laws of Imitation" published in 1890. The concept of progress, and the ideas that invention is rare and that the majority of people have a propensity only for mimicry, are central to the notion of diffusion.

Sir Grafton Elliot Smith, founder of Manchester University's internationally renowned Medical School, at the end of the $19^{\text {th }}$ century was one of the so-called 'Grand Diffusionists'. These were a group of early English and German anthropologists about whom Rogers provides an all too brief, somewhat less than cursory reference. Smith refers in his writings to a number of earlier diffusionists including the 16th century Spanish writer Bernal Diaz. Diaz it seems had attributed the wonderful buildings he saw in the Yucatan peninsula of that period, to middle-eastern Jews of biblical times (Smith, 1933, p. 38). While the provenance of uncorroborated secondhand claims such as this might rightly be questioned, a far more serious oversight by Rogers however must be that of the Society for the Diffusion of Useful Knowledge (SDUK). This British institution was convened in 1825 with an impressive array of distinguished scientists, philosophers, 
politicians, military officers and clergymen - all renowned senior practitioners in their respective fields. Of the 66 founding members, about half were Fellows of the Royal Society.

A publication entitled "The Penny Magazine of the Society for the Diffusion of Useful Knowledge" appeared weekly between 1830 and 1845 and this was distributed across the length and breadth of Great Britain. It was presented in an innovative illustrated format that paved the way for later publications such as The Journal of the National Geographic Society in the US in 1888, nearly sixty years later. One of the Penny Magazine's stated aims was the promotion of literacy, although given the nature and position of some of the committee members it undoubtedly served as a useful medium for political propaganda.

What is interesting and possibly significant about the association with the Royal Society, is that a few years prior to the founding of the SDUK - in 1810 to be precise, the Scottish botanist, Robert Brown was admitted as a Fellow of the Royal Society. Brown was the man upon whose observations the term "Brownian Motion" was coined - that is the diffusion of microscopic particles in fluids. We may speculate as to what connection might have existed between Brown's studies of physical microscopic diffusion processes, and the use of the term 'diffusion' in the anthropological sense of describing the sorts of socio-cultural phenomena that interest us. But neat as it might otherwise have been, Brown unfortunately was never a member of the board of the SDUK.

Other commentators and writers on diffusion who preceded Rogers included Bryce (1914) who wrote about the British Empire and the diffusion of British law throughout the world (we shall return to the relationship between diffusion and imperialism). There were also the aforementioned 'Grand Diffusionists' - Fritz Graebner and Wilhelm Schmidt in Germany, and in England William J. Perry and Sir Grafton Elliot Smith. Their views are epitomized by Smith $(1927,1933)$ who claimed to have found carvings of elephants and scenes from Vedic mythology in Mayan America, as well as Roman helmets in Hawaii. In a nutshell they thought that all culture emanated from a single source; specifically Egypt. However their contemporaries in social anthropology regarded such extreme and uncompromising views as eccentric to say the least.

At that time the counter-argument to diffusion was the 'psychic unity of mankind' - basically a belief that all (isolated) cultures and societies inevitably evolved through fairly predictable stages of growth; from 'primitive' to 'savage' to 'civilized'. Similarities in their respective cultural artifacts and traits were part of a natural and inevitable evolutionary development process (a response to the recent impact of Darwin's work), 
and were not necessarily the result of the sorts of influences necessary for diffusion to have occurred.

In the 1920's Malinowski, one of the most important anthropologists of the 20th century, and considered to be the founder of social anthropology, said that "... culture can only be contracted by contagion, and that man is an imitative animal" (Malinowski, 1927), thereby reinforcing the views of Tarde. There was Wade too (1938), writing on the clandestine organization and diffusion of philosophic ideas in early 18th century France, and Bell (1948) who wrote on the diffusion and decay of Hellenism in Egypt.

These few examples represent only a tiny number of pre-Rogerian diffusion researchers and commentators. There are very many more who worked in this tradition (and rarely uncontentiously), both before and since Rogers's first contribution in the early sixties (Rogers, 1962). However it is the political geographer Blaut's account of diffusion that primarily informs this work (Blaut, 1987, 1992, 1993). Linking diffusion firmly to European colonial expansionism between the $15^{\text {th }}$ century, and its culmination in what Hobsbawm (1987) describes as the Age of Empire, Blaut thus attributes the beginning of diffusionist thinking precisely to 1492 .

\section{4. $1492 \&$ THE EUROPEAN 'MIRACLE'}

In 1492 the opening up of sea routes to the New World in the West, and around the southern tip of Africa to the East marks the beginning of a period of European expansionism that reached its peak in the late 19th century. By that time the British Empire was at its inglorious height and the arguments used to support its activities - the very ideas that underpinned the theory of classical diffusionism, were fully evolved. Although war, invasion, subjugation, slavery and exploitation were all features of European expansionist activity, these were not seen at that time as they might be today. They were the unfortunate effect of having to combat resistance and therefore could be justified. The colonizing Europeans felt they had certain moral duties, and these included bringing civilization to uncivilized savages, the true religion to heathens, and science, technology and other benefits to superstitious natives who were comparable only to children or animals at best. Since animals and children could not 'own' land or property, they (the colonizers) thus had a moral obligation to 'administer' these lands on behalf of the indigenous native sub-species, at least until such time as they might, through proper colonial tutelage, be brought into a state of advanced civilization (this of course represents the 'generous' view!).

Classical diffusionism was the creed that evolved to justify these activities. The supporting 'evidence', mostly taking pseudo-scientific forms 
of argument, fell into various categories that can broadly be identified in terms of biology, and environment, as well as the cultural forms of rationality, technology and society. These arguments are nothing more than fallacious theories that were (and often still are) used as justifications or explanations for the myth of the so-called 'European Miracle'. That is a belief in the innate 'superiority' of Europe and Europeans over the rest of the world.

In a somewhat diluted form, many of these arguments are still used to support diffusionism today. However before looking at some instances of these, it should be noted that sometimes it is difficult if indeed at all possible to distinguish specific issues as belonging to one particular category rather than to another, since some issues are often deeply enmeshed in more than one. It should also be noted that the term 'European' as it is used here is no longer confined to the geographical entity 'Europe', but also now includes the United States, Australia, Japan and other locations to some extent. In other words we are talking about the prevalence of modern Western societies' values and cultures, whose origins were once confined to only to a few Western European countries, but which now are found across the (socalled) developed world.

A brief description of these categories and arguments - a summary indeed of Blaut's (1993) more than excellent account, follows.

\subsection{Biology}

To prove their superiority over others, colonizers (Europeans) have often used 'biological evidence'. This has worked on the two fronts of race and demography. In terms of race, the general assertions have been that Europeans are biologically superior to non-Europeans; they are brighter, better, and more intelligent due to heredity. Some Europeans, most notably those of Nordic stock (the 'master' race) were also considered to be superior to other Europeans. Non-Europeans were regarded as an inferior subrace at best, and at worst were considered not to be of the same species at all. NonNordic Europeans were often considered to have defective genetic materials accounting for 'feeblemindedness' and criminal inclinations. Support for these views saw the introduction of 'race science' into schools biology curricula in pre-WW2 Germany and mass extermination of the Jews by the Nazi regime. It also saw the introduction of eugenicist sterilization programs in the United States and Europe (especially Scandinavia), and one assumes, the euphemistic 'ethnic cleansing' atrocities perpetrated in more recent times in Central Africa and the Balkans.

The demography argument or Malthusian population theory (so named after Thomas Robert Malthus, the 18th century economist and demographer) 
is concerned with population growth, or to put it a slightly different way, the control of sexual desire. Greatly simplified, this says that Europeans exercise a certain 'moral restraint', that allows them to control their sexual drives. They therefore are not inclined to suffer from overpopulation problems. Non-Europeans on the other hand have no such control, and as a result are constantly plagued by shortages of food and other resources necessary to maintain their ever-increasing populations. They therefore also pose a threat to the others.

\subsection{Environment}

Environmental determinism is the theory that the natural environment influences humans without reference to, or the mediation of culture. It is still used to explain the rise of European power and falls into two sets of theories; those used to explain why tropical regions (Africa and South America), and arid regions (Middle East and the Orient) are inferior to cooler regions (Europe) on the one hand. On the other, explanations as to why 'temperate' Europe is far superior to other parts of the world.

Tropical climates inhibit the progress of civilization. In the 19th century this argument was used to show why Africans remained uncivilized and must therefore naturally accept European colonial control. This was one of the core theories of classical diffusionism. The 'tropical-nastiness' doctrine consists of three main theories. The first concerns itself with the supposed negative effect of a hot, humid climate on the human body and mind, the second with supposed inferiority of tropical climates for food production, and the third with the supposed prevalence of disease in tropical regions. Where occasionally tropical regions were conceded as lush and bountiful, the argument went that this then presented too little of a challenge to humanity, and that no progress therefore took place except under colonial guidance. Other circuitous theories disqualify 'the arid Orient' from progress and civilization on the basis that arid regions have been denied the opportunity for development, because aridity necessitates irrigation, and irrigation leads necessarily to the kind of civilization that is historically stagnant.

'Temperate Europe' arguments include claims that northwest Europe represents a unique marriage of farming, iron and rain-watered land with deeper, wetter, more fertile soils that do not require irrigation. This means that farmers don't have to spend as much time at farm work in order to satisfy their needs and quota of surplus, whereas Asian farmers need to work harder to achieve the same product. European superiority due to environment also includes a 'capes and bays' argument - that is, that the peninsulas, bays 
and navigable rivers of Europe provide a natural basis for communication and trade denied to other continents.

\subsection{Rationality}

By the beginning of the 20th century - the heyday of the doctrine of classical diffusionism, most European thinkers came to accept the doctrine of the 'psychic unity of mankind', at least to the extent of agreeing that all of humanity shares a common ability to progress towards modernity. This took the form of a theory that Blaut (1995, p.95) calls the dualistic-developmental conception of human rationality. The elementary dualism was a distinction between the mentality of child and that of adult. The human mind has developed from a prehistoric condition which was mental childhood. NonEuropeans within this theory are seen as undeveloped, and childlike, but given the psychic unity of mankind thesis, they can be brought to adulthood, modernity and rationality through the colonial tutelage of rational Europeans. Ancient people are governed much more by emotion and passion than by intellect, just as is the case with modern children, and with some modification to the theory, the same applies to modern European women. Women too however would be able to experience mental development, and would eventually be rational enough to vote, and to hold public office.

European history is either to be explained as the fruit of mental development or has been intimately accompanied by such development in a process that was fundamentally the same as the psychological development from childhood to adulthood. Europeans became more rational as history progressed just as children acquire rationality in the course of ontogenetic development. The contrast is often also extended to psychotics, who were sometimes seen as having an arrested mental development. At the center of this model is the Rational Modern Adult European Man, contrasted with ancient European man, modern European children, modern European women, as well as modern non-Europeans.

Much of the ideas contained here may be encapsulated in the term 'Weberian', because Max Weber made important use of the idea that capitalism for example, was the culmination of a process of social evolution that reflected intellectual progression, the ascent of rationality from ancient to modern (European) society. Outside of Europe, societies were in varying degrees traditional and irrational.

\subsection{Technology}

When examined more closely, most so-called technological claims for the superiority of Europeans are generally to do with inventiveness rather 
than technological determinism per se, and therefore belong to the 'rationality' argument described above. Nevertheless there are technological claims, though these are just as fallacious as the arguments in the other categories described. Examples of such claims include the invention of the iron stirrup, the horse collar, and three-field crop rotation among others.

The iron stirrup in medieval times permitted a new form of mounted warfare, and created the phenomena of the medieval knight. Since knights became manorial lords, this led to feudalism; a necessary stage in the Weberian evolution of capitalism, and thus the modern Western world.

The horse collar (the discovery of horsepower) transformed agriculture and grain transport in northern Europe by permitting horses to replace oxen for pulling plows and wagons. This led to the intensification and expansion of commerce since horsepower was faster and cheaper. Villages became larger because of an expanded radius of travel from home to field thus allowing villages - or towns as they were becoming, to have a church, a school and a tavern. Boys could thus learn their letters so that there could now be news from distant parts, and so urbanization and preparation for the characteristics of modern city life took place.

Three-field crop rotation was important because it reduced the proportion of fallow land from half to one-third. Oats could be grown more widely, hence a greater use of horsepower, and legumes could be grown resulting in a vastly improved European diet. This in turn explains the expansion of population, the growth and multiplication of cities, the rise of industrial production and the outreach of commerce during medieval times.

\subsection{Society}

At a societal level, various arguments have been proposed to account for European superiority. These fall into a number of sub-domains such as 'state', 'church', 'class' and 'family'. For the purposes of this article, only state and class will be summarized.

The state argument is not too dissimilar to the environmental argument; that the fortuitous location and unique cultures of northern Europe bred a race of freedom-loving, individualistic and antidespotic people from which the modern democratic state, always immanent, naturally and inevitably sprang. In non-Europe a natural irrationality combines with environmental disadvantages to produce for example the kind of 'oriental despotism' found in China, India and the Islamic Middle East. The political infantilism of nonEurope is explained in terms of psychological deficiency, and irrationality in matters of intellectual vitality and innovativeness. Furthermore there is a moral failing in attitudes relating to the desire for progress, resistance to 
domination, and the will to forgo animal pleasures - all of these we will remember, coupled to an inferior natural environment.

Classless regions and peoples are irrelevant to the explanation of Europe's superiority and the world's historical progress because classless societies are necessarily both unprogressive and primitive. Thus in many atlases of world history, sub-Saharan Africa does not exist - or at any rate no maps of Africa are shown from Upper Paleolithic times to the early 16th century. Such arguments typically ascribe causality (towards social 'progress' and modernization) to kings and other elite groups (the history of England is defined by kings and queens), and that the uniquely European phenomena of the medieval aristocracy was the central causal force behind the European miracle. The aristocracy was a band of comrades joined by bonds of feudal loyalty - a democracy in its own right, who also through the acquisition of private property also effectively invented capitalism. Elsewhere the aristocracy was ground under by despotic polity or became corrupted into a caste system such as in India, where the possibility for modernization therefore ceased to exist.

Now that we have established something of the pre-Rogerian tradition of diffusionist thought and at least some of the links between diffusion and colonization, let us turn our attention to the task of constructing a model of diffusion.

\section{BUILDING A MODEL OF DIFFUSION}

Notwithstanding Rogers's definition of diffusionism, Jett and Kraus (1973) note that there is much confusion and misunderstanding surrounding the notion and the term - even they say, by those claiming to be diffusionists! These authors take the trouble to try and clarify the issue (ibid. p.144), thus;

\footnotetext{
"To unravel the facts, we have to distinguish between (a) the locally limited emergence of specific cultural traits, attributable to independent development (free from outside intervention of diffusion) and (b) the geographically separate occurrence of similar (or even identical) culture traits, which can be attributed either to independent parallel development, or to outside influence (diffusion)".
}

Figure 1 illustrates the possibility of diffusion, but also the difficulties associated with its recognition. Diffusionists acknowledge the independent origin of solitary isolated cultural traits, but dispute the possibility of their independent, geographically separate parallel occurrence. Cultural isolationists generally attribute almost all cultural origins to independent development, but presenting this so-called 'cultural problem' as independent development versus diffusion, is to misrepresent it. The quarrel between 
isolationists and diffusionists say these authors, centers on the mode of origin of geographically separate cultural similarities.

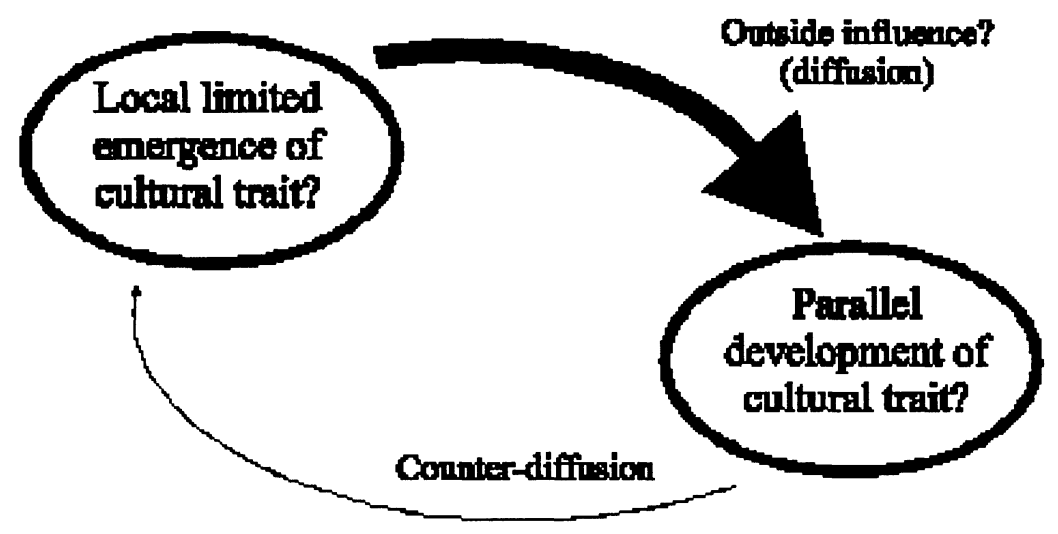

Figure 1. A basic diffusion model

In figure 1, we see that the influence of a trait that has arisen in one (social) system may stimulate the development of the same or a similar trait in another system. None of this is by any means certain - making causal links is rarely easy and never simple. However let us assume the case. Then some features of diffusion are worth noting. The main and obvious one is that influence is overwhelmingly one-way. We may consider the first social system to be where the 'creativity' takes place - the center of innovation, and the other, the recipient community. As we have alluded to previously, diffusion is entirely dependent on the idea that there is a (single) source of innovation, and that others are capable only of imitation. There is however a small feedback trickle from the recipient community - counter-diffusion, because this is invariably negative; we shall see why in a moment, but to all intents and purposes the main process is unidirectional.

Let us return again to Rogers (1995, pp.262-280), because the characteristics of his 'classes' of adopter (table 2) will help us to refine our model further. 
Table 2. Adopter classes and characteristics

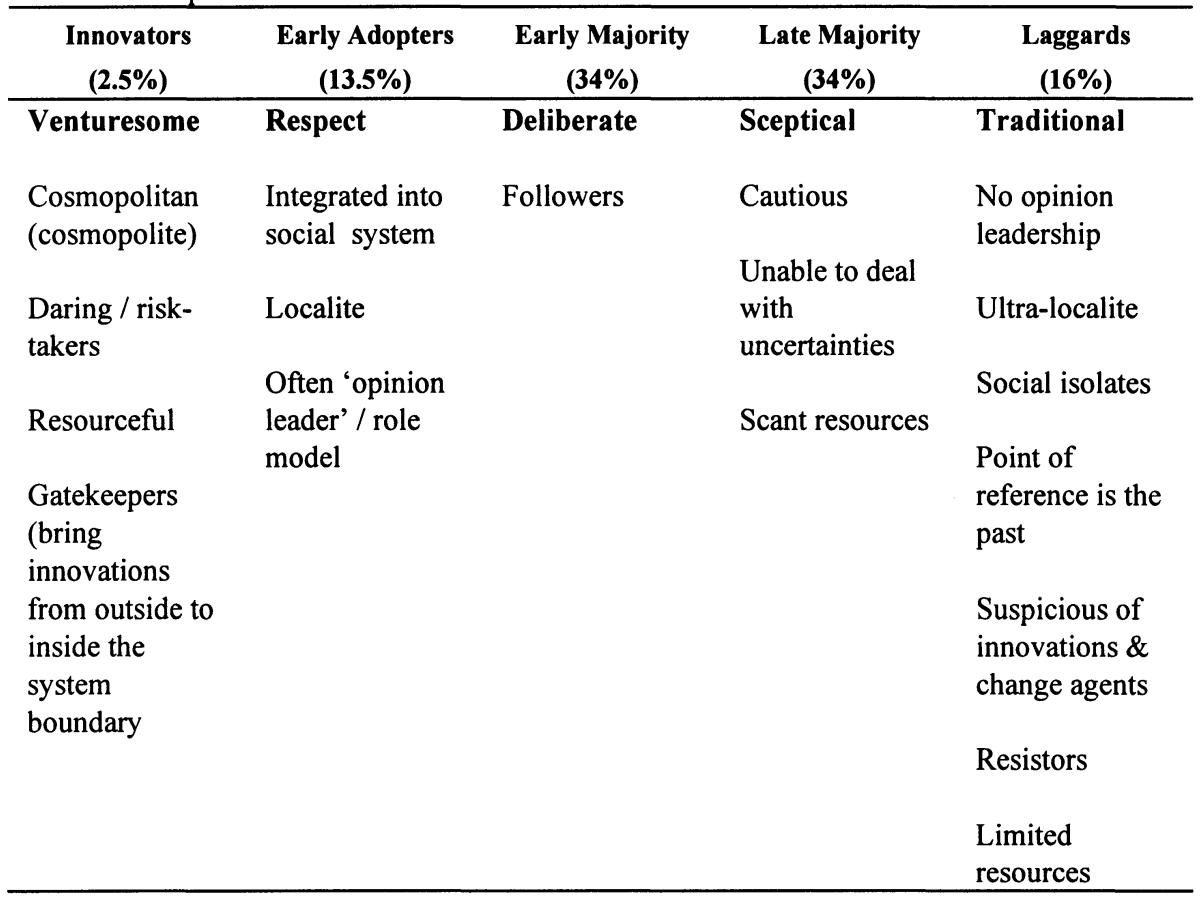

Rogers (1995, p. 262-280) describes the various characteristics and qualities of adopters - from on the one hand 'innovators' - a small minority of resourceful risk-takers, progressive and cosmopolitan, and characterized by the term 'venturesome', to on the other hand 'laggards'. These by comparison are backward looking country bumpkins afraid of any kind of change, though somewhat more politely described as 'traditional'. As a matter of interest this author has asked many people over the years to classify themselves into one or another of these categories - never once has anyone ever described themselves as a 


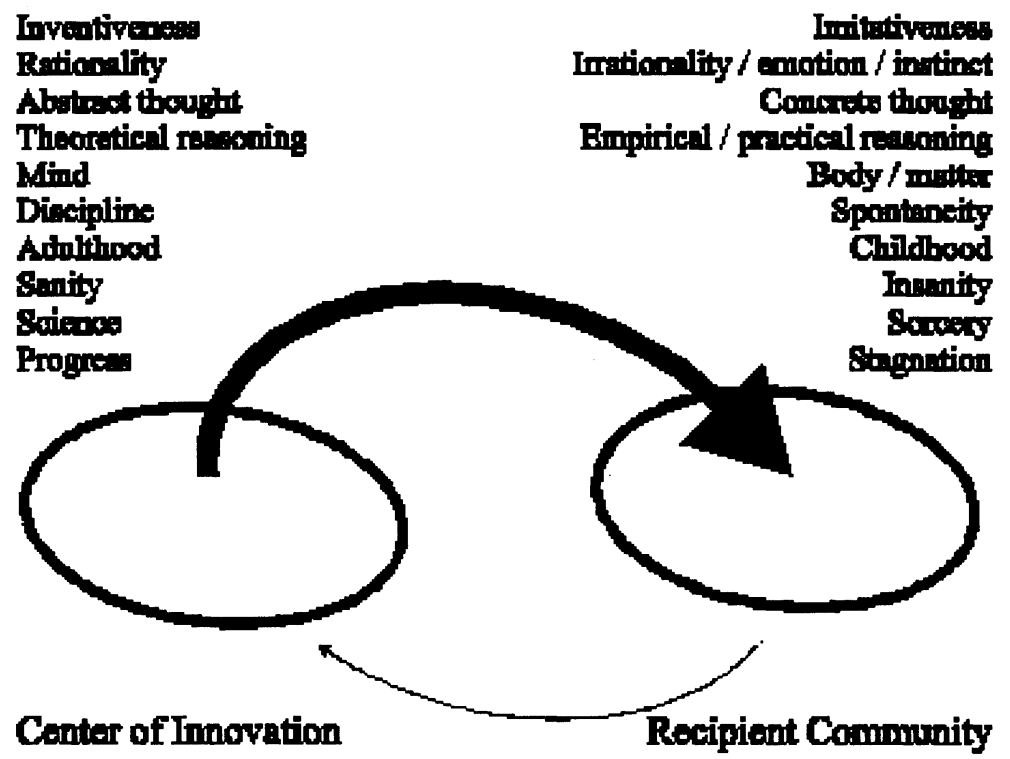

Figure 2. Diffusion/colonization model

'laggard', although according to Rogers $16 \%$ of us are! If we flatten or polarize the attributes of the so-called 'classes' of adopter into just two groups - innovators and recipients, by using characteristics similar to or at least encapsulating those offered by Rogers (Blaut, 1993), we now have a model of diffusion which more accurately reflects its colonial connections (figure 2). Now we can see why the 'feedback' or counter-diffusion flow is always negative. From the center of creativity flows reason, science and progress, while from the recipient flows only stagnation, insanity and irrationality. Blaut has called this the 'Aids out of Africa' syndrome, but 'Voodoo from Haiti', 'nasty tropics' or any other such phrase equally conveys the sentiment, particularly when it is compared for example to 'nice temperate Europe'. Now we can see how colonization can be, or at least has been justified (at least to the colonizers) - they bring knowledge, progress and reason where in their view only ignorance, superstition and sorcery prevailed.

\section{DISCUSSION}

Some effort has been made in this paper to try and show the relationship between colonization and diffusionism, and to construct and present a model of diffusion that highlights those similarities. The colonial activities of 
conquering, settling and exploiting are diffusion in practice, but is there any relevance in this for IS community?

We may feel that we are not affected by these ideas, but consider the following table (table 3), which is part of a correspondence that was circulated to the membership of ISWorld towards the end of 1999 by a person well-known to the international IS research community. It was sent ostensibly as 'humor'. However knowing the sender it must be said that it is not even remotely possible that sender could ever have meant anything unkind by it.

Table 3. Rural American computer terms translated

\begin{tabular}{ll} 
Log On & Make the fire hotter \\
Log Off & Don't add any more wood \\
Monitor & Keep an eye on that fire \\
Download & Getting' the firewood off the buggy \\
Floppy Disk & What you git from carryin' too much firewood \\
RAM & The thing what splits the firewood \\
Hard Drive & Getting' home in a heavy rainstorm \\
Prompt & What the postal service used to be \\
Window & What to shut when it's cold outside \\
Screen & What to shut in mosquito season \\
Byte & What the mosquito's do \\
Bit & What the mosquito's did \\
Mega Byte & What the Arkansas mosquito's do \\
Micro Chip & What's left in the bag after you eat the crisps \\
Modem & What you did to the hay fields \\
Dot Matrix & Ol' Dan Matrix's wife \\
\hline
\end{tabular}

Funny or not, it has the effect of unfairly belittling naïve users who are not given a voice to speak for themselves. And who has not heard stories of naïve users trying to use the mouse as a foot-pedal, of the CD drawer as a coffee-cup holder? The implications are not so different from earlier views of the (noble or otherwise) savage that enabled the colonizers to take possession of their lands and properties. I recall one senior systems professional saying "I don't give them (users) what they want...I give them what they need". This is more subtle perhaps than the users who said that the latest IT department's initiative was just another "empire-building exercise", but the colonizing attitude still comes through. How surprised should we be then that perhaps up to $80 \%$ of new systems implementation initiatives 'fail'?

What we can learn from colonization, is that sooner or later the 'colony' is going to become independent by one means or another - either by previous arrangement such as in the handing back to China of Hong Kong on 1st July 1997 after originally being ceded to Britain in 1842, or by a 
unilateral declaration of independence such as that made by Ian Smith on behalf of the former Rhodesia, on the 11th November 1965. It is perhaps too early to make judgements about the example of Hong Kong, but in the latter case today ( 35 years on), problems continue to make international news headlines - poor black Zimbabweans illegally occupy white-owned farms, and are encouraged to do so by anti-colonial rhetoric of that country's leader, Robert Mugabe.

In the IT/IS domain, we see more and more of the IT Department's traditional customer base declare a kind of independence as they ask why they still need a central IT department. As technology becomes increasingly easier to acquire and use, and the departments grow their own in-house expertise, they are inevitably beginning to question the relationship they have had with traditional IT professionals. What is needed is a more equitable relationship based not as it so often has been in the past on exploitation, but instead on trust and mutual respect. Over the last three decades various attempts have been made to address these problems, including for example the Scandinavian 'Collective Resource Approach' (Ehn and Kyng, 1987), in the UK Enid Mumford's ETHICS approach (Mumford, 1983), Checkland's Soft Systems Methodology (Checkland, 1981), as well as hybrids combining various aspects of each (Avison and Wood-Harper, 1990). As we attempt to design and implement new systems to support evolving business forms for the new millennium, will it prove that we have indeed learned something? Or will that insidious human propensity to colonize, either under the guise of 'diffusion' or perhaps some other euphemism continue to get the better of us?

\section{ACKNOWLEDGEMENTS}

My warmest thanks to Richard Vidgen and to Karlheinz Kautz for their comments on an earlier draft of this paper. Thanks also to my fellow IRIS23 team members (Kari Thorensen, Helle Zinner Henriksen, Petri Hallikainen \& Kari Nurmimäki, Katarina Riabacke, Jan Kristensen, Ingegerd Andersson $\&$ Kerstin Nilsson), for their supportive and insightful comments on this work at the IS world's oldest annual event (and its very best-kept secret!). Thanks also to the 8.6 reviewers for their critical comments and their helpful suggestions for improving the paper. 


\section{REFERENCES}

Attewell, P., (1992), 'Technology, diffusion and organizational learning: the case of business computing', in Organization Science, Vol. 3 (1), pp. 1-19.

Avison, D. and Wood-Harper, T., (1990), Multiview: an exploration in information systems development, Blackwell Scientific Publications, Oxford.

Bell, H. I., (1948), Egypt: from Alexander the Great to the Arab conquest: a study in the diffusion and decay of Hellenism, Oxford University Press, Oxford.

Blaut, J. M., (1987), 'Diffusionism: A Uniformitarian critique', in Annals of the Association of American Geographers, Vol. 77 (1), pp. 30-47.

Blaut, J. M., (1992), 'Fourteen ninety-two', in Political Geography, Vol. 11 (3), pp. 355-385.

Blaut, J. M., (1993), The colonizer's model of the world: geographical diffusionism and Eurocentric history, The Guilford Press, New York.

Bowler, P. J., (1989), The Invention of Progress, Basil Blackwell, Oxford.

Bryce, J., (1914), The ancient Roman Empire and the British Empire in India / The diffusion of Roman and English law throughout the world: two historical studies, Oxford University Press, London.

Checkland, P., (1981), Systems Thinking, Systems Practice, John Wiley and Sons, Winchester.

Checkland, P. and Holwell, S., (1998), Information, Systems and Information Systems: making sense of the field, John Wiley \& Sons, Chichester.

Checkland, P. and Scholes, J., (1990), Soft Systems Methodology in Action, John Wiley and Sons, Winchester.

Ehn, P. and Kyng, M., (1987), 'System design and industrial democracy', in Bjerknes, G., Ehn, P. and Kyng, M., (Eds.), Computers and democracy: a Scandinavian challenge, Avebury, Aldershot, pp. 17-57.

Fichman, R. G., (1992), 'Information technology diffusion: a review of empirical research', in 13th International Conference on Information Systems (ICIS) Dallas.

Hobsbawm, E. J., (1987), The Age of Empire: 1875 - 1914, Weindenfeld \& Nicolson, London.

Ives, B. and Olson, M. H., (1984), 'User involvement and MIS success: A review of research', in Management Science, Vol. 30 (5), pp. 586-603.

Jett, S. C. and Kraus, G., (1973), 'A discussion on diffusionism', in The New Diffusionist, Vol. 3 (13), pp. 142-154.

Kautz, K. and McMaster, T., (1994), 'The failure to introduce systems development methods: a factor-based analysis', in Levine, L., (Eds.), Diffusion, transfer and implementation of information technology, Elsevier Science BV, Amsterdam, pp. 275-287.

Kautz, K. and Pries-Heje, J., (Eds.), (1996), Diffusion and adoption of information technology, Chapman and Hall, London.

Kwon, T. H. and Zmud, R. W., (1987), 'Unifying the fragmented models of information systems implementation', in Boland, R. J. and Hirschheim, R. A., (Eds.), Critical Issues in Information Systems Research, John Wiley \& Sons, Chichester.

Latour, B., (1987), Science in action: how to follow scientists and engineers through society, Harvard University Press, Cambridge, MA.

Latour, B., (1993), We have never been modern, Harvester Wheatsheaf, Hemell Hempstead. 
Levine, L., (Ed.), (1994), Diffusion, Transfer and Implementation of Information Technology, Elsevier Science BV, Amsterdam.

Lyytinen, K. and Hirschheim, R., (1987), 'Information systems failures - a survey and classification of the empirical literature', (Eds.), Oxford Surveys in Information Technology, Vol. 4 Oxford University Press, Oxford, pp. 257-309.

Malinowski, B., (1927), 'The life of culture', in Smith, G. E., (Eds.), Culture: the diffusion controversy, Norton, New York, pp. ??

Markus, M. L., (1983), 'Power, politics and MIS implementation', in Communication of the ACM, Vol. 26 (6), pp. 430-444.

McMaster, T., Vidgen, R. T. and Wastell, D. G., (1997a), 'Technology transfer -- diffusion or translation?', in McMaster, T., Mumford, E., Swanson, E. B., Warboys, B. and Wastell, D., (Eds.), Facilitating technology transfer through partnership: Learning from practice and research, Chapman and Hall, London, pp. 64-75.

McMaster, T., Mumford, E., Swanson, E. B., Warboys, B. and Wastell, D., (Eds.), (1997b), Facilitating technology transfer through partnership: Learning from practice and research, Chapman and Hall, London.

McMaster, T., Vidgen, R. T. and Wastell, D. G., (1999), 'Networks of association and due process in IS development', in Larsen, T. J., Levine, L. and DeGross, J. I., (Eds.), Information systems: current issues and future changes, IFIP, Laxenburg, pp. 341-357.

Mumford, E., (1983), Designing human systems for new technology: The ETHICS method, Manchester Business School, Manchester.

Rogers, E. M., (1962), Diffusion of innovations, The Free Press, New York.

Rogers, E. M., (1983), Diffusion of innovations, The Free Press, New York.

Rogers, E. M., (1995), Diffusion of innovations, The Free Press, New York.

Smith, G. E., (Ed.), (1927), Culture: The Diffusion Controversy, Norton, New York.

Smith, G. E., (1933), The diffusion of culture, Watts \& Co, London.

Tornatzky, L. G. and Klein, L., (1982), 'Innovation characteristics and innovation implementation: a meta analysis of findings', in IEEE Transactions on Engineering Management, Vol. 29 (1), pp. 28-45.

Vidgen, R. and McMaster, T., (1996), 'Black boxes, non-human stakeholders and the translation of IT through mediation', in Orlikowski, W. J., Walsham, G., Jones, M. and DeGross, J. I., (Eds.), Information technology and changes in organizational work, Chapman and Hall, London, pp. 250-271.

Wade, I. O., (1938), The clandestine organization and diffusion of philosophic ideas in France from 1700 to 1750 , Princeton University Press, Princeton.

Zmud, R. W., (1984), 'An examination of 'push-pull' theory applied to process innovation in knowledge work', in Management Science, Vol. 30 (6), pp. 727-738. 